\title{
Review
}

\section{Static Magnetic Field Therapy: A Critical Review of Treatment Parameters}

\author{
Agatha P. Colbert ${ }^{1}$, Helané Wahbeh ${ }^{2}$, Noelle Harling ${ }^{1}$, Erin Connelly ${ }^{1}$, \\ Heather C. Schiffke ${ }^{1}$, Cora Forsten ${ }^{1}$, William L. Gregory ${ }^{1,2}$, Marko S. Markov ${ }^{3}$, \\ James J. Souder ${ }^{4}$, Patricia Elmer ${ }^{2}$ and Valerie King $^{2}$
}

${ }^{1}$ Helfgott Research Institute, National College of Natural Medicine Portland, OR, ${ }^{2}$ Oregon Health and Science University, Portland, OR, ${ }^{3}$ Research International, Williamsville NY and ${ }^{4}$ Painfree Lifestyles, Bracey VA, USA

\begin{abstract}
Static magnetic field (SMF) therapy, applied via a permanent magnet attached to the skin, is used by people worldwide for self-care. Despite a lack of established SMF dosage and treatment regimens, multiple studies are conducted to evaluate SMF therapy effectiveness. Our objectives in conducting this review are to:(i) summarize SMF research conducted in humans; (ii) critically evaluate reporting quality of SMF dosages and treatment parameters and (iii) propose a set of criteria for reporting SMF treatment parameters in future clinical trials. We searched 27 electronic databases and reference lists. Only English language human studies were included. Excluded were studies of electromagnetic fields, transcranial magnetic stimulation, magnets placed on acupuncture points, animal studies, abstracts, posters and editorials. Data were extracted on clinical indication, study design and 10 essential SMF parameters. Three reviewers assessed quality of reporting and calculated a quality assessment score for each of the 10 treatment parameters. Fifty-six studies were reviewed, 42 conducted in patient populations and 14 in healthy volunteers. The SMF treatment parameters most often and most completely described were site of application, magnet support device and frequency and duration of application. Least often and least completely described were characteristics of the SMF: magnet dimensions, measured field strength and estimated distance of the magnet from the target tissue. Thirty-four $(61 \%)$ of studies failed to provide enough detail about SMF dosage to permit protocol replication by other investigators. Our findings highlight the need to optimize SMF dosing parameters for individual clinical conditions before proceeding to a full-scale clinical trial.
\end{abstract}

\section{Introduction}

The application of permanent magnets for treating specific medical problems such as arthritis, chronic pain syndromes, wound healing, insomnia, headache and others has steadily increased during the last decade. Data Research-2000 reported $\$ 350$ million in sales of therapeutic magnets in the USA and $\$ 4$ billion

For reprints and all correspondence: Dr Agatha P. Colbert, Helfgott Research Institute, National College of Natural Medicine, 049 SW, Porter Street, Portland, OR 97291, USA. Tel: + 1 (503) 552-1745; Fax: +1 (503) 227-3750; E-mail: acolbert@ncnm.edu worldwide in 1999. Magnets marketed directly to consumers are considered safe by the National Center of Complementary and Alternative Medicine (NCCAM) http://nccam.nih.gov/health/magnet/magnet.htm.

Results from basic science research demonstrating certain biological effects of static magnetic field (SMF) therapy provide a rationale for investigating potential clinical benefits of SMFs (1-5). In addition, NCCAM has funded human studies to evaluate the effectiveness of SMFs for patients with fibromyalgia (6) and carpal tunnel syndrome (7). Despite the lack of scientific recommendations for SMF dosage and treatment 
regimens, multiple clinical trials have been conducted to evaluate SMF efficacy. Dosing parameters such as the optimal SMF strength, frequency and duration of magnet application and at what time point during the course of an illness or injury the SMF should be applied, are not established for any specific clinical indication.

As we begin to evaluate whether SMF therapy is efficacious in humans, a critical need exists for understanding and precisely defining SMF dosages and treatment regimens. Our objectives for this critical review are to: (i) summarize SMF studies involving the application of permanent magnets in humans; (ii) critically evaluate the reporting quality of 10 essential SMF dosing and treatment parameters and (iii) propose a set of criteria for reporting SMF treatment parameters in future clinical trials.

This review does not report clinical outcomes because, during a preliminary evaluation of the identified studies, it was apparent that many lacked a sufficiently detailed description of SMF dosage and treatment parameters to characterize the SMF dose delivered to the target tissue. We reasoned that if the SMF dose were inadequate or inappropriate for the clinical indication, inferences drawn from the reported results might be misleading.

\section{Methods}

\section{Data Sources and Search Strategy}

A professional librarian $(\mathrm{NH})$ searched 27 electronic databases from the time each database was developed through September 30, 2006, to identify clinical studies involving the use of SMF in humans (Table 1). Various search strategies were employed depending on the size and scope of the database. In some cases, a simple keyword search using the term 'magnet' was sufficient to retrieve relevant articles with reasonable precision and recall. In other cases, a more sophisticated strategy involving multiple synonyms for SMF therapy, subject headings, truncation and excluded terms was required. The primary author examined the results of the searches to identify articles for analysis, screening by title, abstract when it was available and full text where necessary. The bibliographies from relevant original research, reviews (8-10), and a key textbook in the SMF field (11) were searched to identify additional references.

\section{Inclusion and Exclusion Criteria}

Studies were selected for inclusion using the following criteria.

\section{Publication type}

Only English language articles were identified due to limited funding for accurate translation. Abstracts,
Table 1. Databases searched

\begin{tabular}{|c|c|}
\hline Database & Coverage dates \\
\hline Acubriefs.com & 1999 till present \\
\hline $\begin{array}{l}\text { Agency for Healthcare Research } \\
\text { and Quality (AHRQ) website }\end{array}$ & Website: no coverage dates given \\
\hline Alt HealthWatch & 1984 to September 2006 \\
\hline AMED & ca. 1980 till present \\
\hline Annual Reviews Online & 1932-1999 \\
\hline $\begin{array}{l}\text { Applied Science and Technology } \\
\text { Index }\end{array}$ & 1983 till present \\
\hline ArticleFirst & 1990 till present \\
\hline BIOSIS Previews & 1990 till present \\
\hline China Academic Journals (CAJ) & 1994 till present \\
\hline CINALH & 1982 till present \\
\hline Datadiwan & $\begin{array}{l}\text { Unable to determine; no response } \\
\text { from database producer }\end{array}$ \\
\hline $\begin{array}{l}\text { DIMDI (German Institute of } \\
\text { Medical Documentation and } \\
\text { Information) }\end{array}$ & $\begin{array}{l}\text { Federated search of multiple } \\
\text { databases - various coverage } \\
\text { dates }\end{array}$ \\
\hline $\begin{array}{l}\text { Dissertation Abstracts } \\
\text { International }\end{array}$ & 1861 till present \\
\hline EMBASE.com & 1974 till present + MEDLINE \\
\hline ExtraMED & $1992-2000$ \\
\hline Global Health & 1973 till present \\
\hline $\begin{array}{r}\text { HOM-INFORM (British } \\
\text { Homeopathic Library) }\end{array}$ & $\begin{array}{l}\text { Unable to determine; no response } \\
\text { from database producer }\end{array}$ \\
\hline Index to Chiropractic Literature & 1985 till present \\
\hline $\begin{array}{l}\text { JICST-Eplus_Japanese Science \& } \\
\text { Technology }\end{array}$ & 1985 till present \\
\hline MANTIS & 1900 till present \\
\hline MedicLatina & 1998 till present \\
\hline Natural Standard & $\begin{array}{l}\text { N/A (Periodically updated- } \\
\text { monograph) }\end{array}$ \\
\hline $\begin{array}{l}\text { NHS Centre for Reviews and } \\
\text { Dissemination }\end{array}$ & 1994 till present \\
\hline PASCAL & 1973 till present \\
\hline PubMed & 1950 till present \\
\hline $\begin{array}{l}\text { ScienceDirect Health \& Life } \\
\text { Sciences }\end{array}$ & 1996 till present \\
\hline SPORTDiscus & 1830 till present \\
\hline
\end{tabular}

posters and editorials were excluded because they were unlikely to provide sufficient information with which to evaluate the SMF treatment parameters.

\section{Study design}

Clinical trials, case series, case reports and observational studies were included because our goal was to summarize and evaluate all SMF treatment parameters that have been described.

\section{Clinical indication}

We included studies involving any clinical diagnosis or medical condition in humans. Studies evaluating 
physiological change as a result of magnet application in healthy volunteers were also included.

\section{Type of magnetic field therapy}

Only studies involving the application of SMFs via a permanent magnet were included. Excluded were studies reporting on electromagnetic field therapy, magnetic fields generated by applying DC to a coil, transcranial magnetic stimulation. Also excluded were studies reporting on the use of magnets on acupuncture points. We believe the stimulation of acupuncture points by means of a magnetic field may work via a systemic mechanism (12) different from that occurring as a result of a magnetic field applied directly to an anatomical/ pathological target tissue.

\section{Data Extraction}

Data were extracted from each article on clinical indication, study design and 10 essential SMF treatment parameters. An 'essential treatment parameter' was defined as a key component of the SMF dosage or treatment regimen that needed to be clearly described to characterize the magnetic field dose that was delivered to the target tissue. The 56 articles $(6,13-67)$ that met our inclusion/exclusion criteria were randomly distributed to five data extractors.

\section{Quality Assessment (QA) for Reporting SMF Treatment Parameters}

A QA score was developed to quantify how completely each of 10 dosing parameters: SMF characteristics (magnet materials, dimensions, pole configuration, field strength); SMF application (frequency, duration, site of application and support device) and target (target tissue and distance of magnet from target tissue) was described. Two points were given if a parameter was described in enough detail to allow replication of the study protocol by other investigators. One point was given if the parameter was only partially described but enough detail was given to make reasonable inferences about that parameter. For example, if the magnet material was not described but the manufacturer's name (e.g. Bioflex) was provided, and one of the evaluators was familiar enough with that company's products to know that the product was most likely a flexible-type magnet, one point was given. One point was also given if the target tissue was not specifically named, but implied. For example, when dysmenorrhea was treated by placing a magnet over the lower abdomen, the evaluators assumed the target was the uterus. The evaluators might also have inferred that the target was a trigger point on the abdominal wall. Zero points were assigned if the essential parameter was not described at all. A perfect QA score is 20 .

Three evaluators (APC, a clinician researcher with 14 years clinical experience in the therapeutic use of SMFs; MM, a biophysicist with 32 years research experience in SMFs and JS, a magnetic product developer with 15 years experience in magnet design and manufacturing) met to discuss the extracted data and assign a consensus QA score for reporting each of the 10 essential SMF treatment parameters in the 56 studies.

\section{Results}

The complete set of extracted data on 10 essential SMF treatment parameters and the QA scores for the 56 studies are summarized in supplementary Tables 1 and 2 .

\section{Description of Studies}

Forty-two studies were conducted in patient populations (supplementary Table 1) and 14 in healthy volunteers (supplementary Table 2). The varied clinical conditions and physiological responses that were evaluated are listed in Table 2. In the 56 studies, 39 different physiological or pathological conditions are represented. The most common clinical diagnosis was osteoarthritis of the knee. Other conditions were as diverse as peripheral neuropathy, peripheral vascular disease, wound and ulcer healing, obstructive sleep apnea, tinnitus and a variety

Table 2. Conditions treated with static magnetic field therapy

\begin{tabular}{|c|c|}
\hline Physiological Conditions $^{\mathrm{a}}$ & Clinical Conditions ${ }^{\mathrm{b}}$ \\
\hline $\begin{array}{l}\text { Muscle strength/physical function } \\
\quad(21,51,55,58,31)\end{array}$ & $\begin{array}{l}\text { Chronic pain - headache }(40) \text {, neck }(37) \text {, shoulder }(38,39,47) \text {, low back }(25,35,41,63) \text {, abdominal/genital } \\
(36) \text {, pelvic }(18,29) \text {, foot }(20,60,61,64-66) \text {, fibromyalgia }(6,23) \text {, myofascial pain }(48,59) \text {, carpal tunnel } \\
\text { syndrome }(19,62)\end{array}$ \\
\hline $\mathrm{HR}$ and $\mathrm{BP}(33)$ & Post surgical - suction lipectomy (42), hallux valgus (54) \\
\hline \multirow{2}{*}{$\begin{array}{l}\text { Blood flow/temperature } \\
\quad(14,43-45,56)\end{array}$} & Peripheral vascular disease/leg or foot ulcerations - $(13,28,30,57)$ \\
\hline & $\begin{array}{l}\text { Miscellaneous - bronchopulmonary dysplasia (22), sleep apnea }(26,27) \text {, urinary incontinence (15), tinnitus (24), } \\
\text { orthodontic safety }(16) \text {, malignancy }(50)\end{array}$ \\
\hline
\end{tabular}

${ }^{\mathrm{a}}$ Physiological outcomes evaluated in healthy volunteers; ${ }^{\mathrm{b}}$ Clinical indications in various patient populations. 


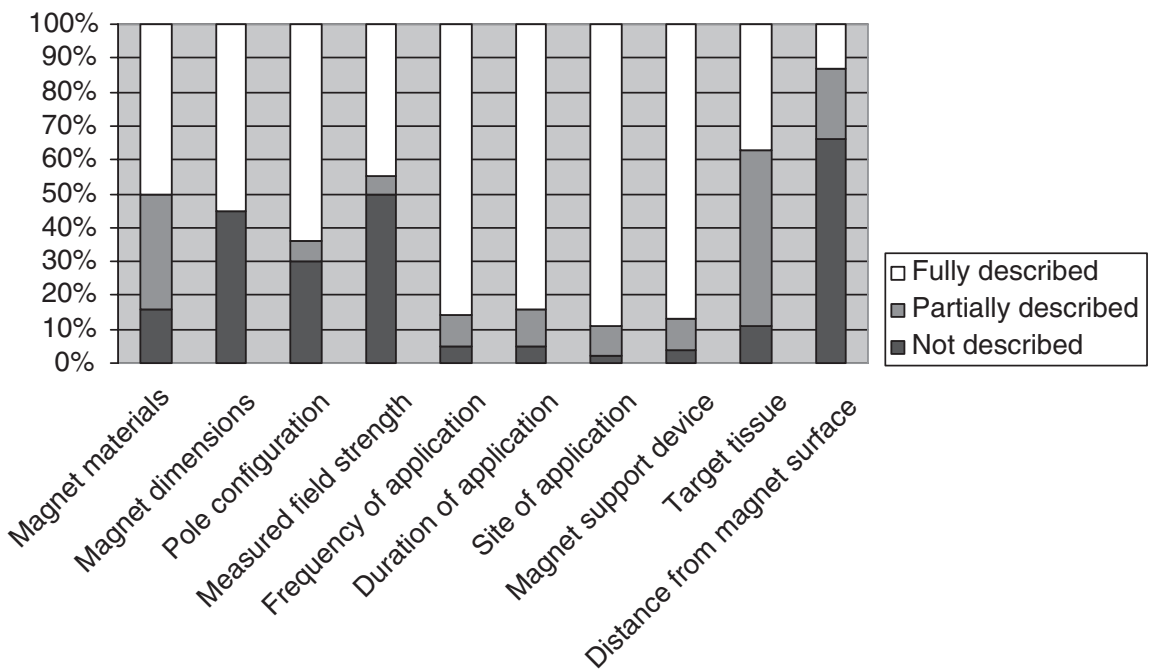

Figure 1. Quality of reporting 10 static magnetic field (SMF) dosage and treatment parameters was assessed in 56 human studies. Quality Assessment (QA) score 2 = parameter is reported with enough detail for study replication; 1 = parameter is reported with insufficient detail to allow study replication or accurate comparison of results with other studies; $0=$ parameter is not reported.

of chronic pain syndromes. The physiological outcomes measured were also disparate including: improvement in muscle strength, muscle soreness post exercise, postural sway, fine touch, blood flow and heart rate and blood pressure. The majority of studies were randomized controlled trials (RCTs) $(n=41)$ that included both crossover designs and within-subject comparisons. We identified only two Phase I/II studies that assessed dose ranging or an evaluation of dosing regimens (16-50).

Since there were two distinct categories of studies (healthy volunteers and patient populations), a multivariate analysis (MANOVA) was used to compare them on the 10 treatment parameters evaluated by QA score. The MANOVA was not significant, $P>0.20$. Thus, there was no need to consider reporting quantitative or qualitative results for the two groups separately.

\section{QA Scores}

Percentage of the 56 studies that scored either 2 (fully described), 1 (partially described) or 0 (not described) on each essential treatment is delineated in Fig. 1. Two studies (45-67) out of 56 received a perfect QA score of 20 for detailed reporting of SMF dosing parameters. Twenty-four studies (43\%) scored 15-19 for adequacy of reporting SMF treatment parameters; 20 studies (36\%) scored 10-14: 9 studies (16\%) scored 5-9 and one scored less than 5 . The dosing parameters most consistently well reported were site, frequency and duration of magnet application. The parameters most often poorly reported were characteristics of the magnet (magnet dimensions, field strength measured at the magnet surface) and estimated distance of the magnet from the target tissue. Only $22(39 \%)$ of 56 articles $(6,14,16,18,23,29,31-35$, $40-42,44,45,52,53,56,59,64,67)$ provided sufficiently detailed information on SMF treatment parameters to permit other investigators to attempt study replication.

\section{Discussion}

This critical review was undertaken to summarize SMF research involving the application of magnets in humans; to critically evaluate quality of reporting 10 essential SMF dosage and treatment parameters and to propose a set of criteria for reporting SMF treatment parameters in future clinical trials.

Since research on SMF therapy in humans is in an emerging state, it is vital that we lay the groundwork for the rigorous conduct of future clinical trials. A fundamental component of trial methodology is the assurance that optimal SMF dosage and treatment parameters are established for each clinical condition under study. If the applied SMF is of insufficient strength to reach its target or if the frequency or duration of application is inadequate for the medical condition, trial results might be invalid or misleading. Such a situation could be likened to conducting a trial to evaluate the effectiveness of the antibiotic doxycycline for treating Mycoplasma pneumonia. If patients in the study are given a single $100 \mathrm{mg}$ dose of the antibiotic, the results might show no significant improvement. It would, however, be erroneous to infer from these results that doxycycline is ineffective for treating Mycoplasma pneumonia.

In order to judge the adequacy of SMF exposure for a particular clinical indication, the magnetic dosage and treatment regimens need to be reported explicitly. Clear reporting also allows for accurate replication of study protocols and comparison of results between studies. This critical review revealed that the majority 
of published studies (61\%) failed to report enough detail about 10 essential SMF dosage and/or treatment parameters to characterize the SMF that actually reached the intended target tissue. Of the 10 essential SMF treatment parameters reported, only site, frequency and duration of magnet application and magnetic support device were adequately described. Descriptions of three other essential treatment parameters specific to SMF dosing, i.e. identification of the target tissue, measurement of the SMF at the magnet's surface and estimation of distance of target tissue from the magnet, were either not described or only partially described in a preponderance of studies (Fig. 1).

In addition, the SMF dosage reported in many of the studies revealed a limited understanding, on the part of the investigators, of the physical and biophysical characteristics of magnets that determine the SMF dose ultimately delivered to the target tissue. Four studies provided contradictory information about the material composition of the magnetic devices applied (31, 44, $55,61)$. Other studies provided ambiguous descriptions of the magnetic strength, by not defining whether they were reporting the manufacturer's Gauss rating or the surface field strength. Approximately one-half of the investigators $(13,15,17,21,22,24,26-31,36,40,43,46-49,51$, $54,55,58-62,68)$ failed to record measurements of the field strength at the surface of their magnets. In 16 studies $(15-17,19,21,26,27,39,46,48,49,51,54,56$, $58,63)$ there is no mention of which pole configuration was applied or if the side of the magnet facing the skin was north, south or alternating polarity.

Despite a lack of established recommendations or guidelines for SMF dosing regimens, 41 RCTs, were conducted without prior benefit of Phase I or II trials to optimize SMF dosage and treatment regimens for the condition being treated. In fact, this review identified only two early phase studies that addressed toxicity and/ or dose ranging of SMFs $(16,50)$.

\section{Limitations to this review}

There are a number of limitations in our study. First, we reviewed only the English language literature. Use of therapeutic magnets has a long history in China, Japan and the former Eastern European Bloc countries. Also, several Asian manufacturers that produce magnetic bracelets and necklaces have an extensive literature on clinical usage. Second, although we found a large body of literature reporting the use of magnets on acupuncture points, these studies were excluded because we believe that the practice of acupuncture (a systemic approach) entails a different therapeutic paradigm than direct application of the magnet to a localized anatomical site. Third, evaluators were not blinded to the studies they scored. Since the available clinical SMF research at this time is so small, the three evaluators were already familiar with many of the studies, making it impossible to blind them as to authorship. Fourth, our search ended on September 30, 2006, and does not include any publications after that date.

\section{Conclusion and Directions for Future Research}

Complete descriptions of the SMF dose that was applied to human participants are notably lacking in the majority of SMF therapy studies published to date. Without knowing the SMF dose that was delivered to the target tissue, we cannot draw meaningful inferences from clinical trial results. As research on SMF therapy progresses, engineers, physicists and clinicians need to continue to work together to optimize SMF dosage and treatment parameters for each clinical condition. Future publication of SMF studies should include an explicit assessment of the SMF dosage and treatment parameters outlined in this review, so as to be able to replicate previous studies, validly assess outcomes and make objective, scientific comparisons between studies.

\section{Supplementary Data}

Supplementary data are available at eCAM Online.

\section{References}

1. Markov MS, Pilla AA. Weak static magnetic field modulation of myosin phosphorylation in a cell-free preparation: calcium dependence. Bioelectrochem Bioenerg 1997;43:233-8.

2. McKay JC, Prato FS, Thomas AW. A literature review: the effects of magnetic field exposure on blood flow and blood vessels in the microvasculature. Bioelectromagnetics 2007;28:81-98.

3. Taniguchi N, Kanai S, Kawamoto M, Endo H, Higashino H. Study on application of static magnetic field for adjuvant arthritis rats. Evid Based Complement Alternat Med 2004;1:187-91.

4. Xu S, Tomita N, Ikeuchi K, Ikada Y. Recovery of smallsized blood vessels in ischemic bone under static magnetic field. Evid Based Complement Alternat Med 2007;4:59-63.

5. Morris CE, Skalak TC. Chronic static magnetic field exposure alters microvessel enlargement resulting from surgical intervention. J Appl Physiol 2007;103:629-36.

6. Alfano AP, Taylor AG, Foresman PA, Dunkl PR, McConnell GG, Conaway MR, et al. Static magnetic fields for treatment of fibromyalgia: a randomized controlled trial. $J$ Alternat Complement Med 2001;7:53-64.

7. Colbert A. Carpal Tunnel Syndrome and Static Magnetic Field Therapy: CRISP database, 2006-2009, http://crisp.cit.nih.gov/crisp/ crisp_query.generate_screen

8. Ratterman R, Secrest J, Norwood B, Ch'ien AP. Magnet therapy: what's the attraction? $J$ Am Acad Nurse Pract 2002;14:347-53.

9. Eccles NK. A critical review of randomized controlled trials of static magnets for pain relief. $J$ Alternat Complement Med 2005; 11:495-509.

10. Wasiak J, Anderson JN. Do magnets alleviate chronic low-back pain? Med J Aust 2001;174:659.

11. Rosch PJ, Markov MS. Bioelectromagnetic Medicine. New York: Marcel Dekker, 2004.

12. Markov M, Hazlewood C, Ericsson A. Systemic effect: a new approach to magnetic field therapy. Environmentalist 2005;25:121-30.

13. Ashford RL, Bates AL. A pilot study into the effectiveness of magnetic insoles in stimulating the microcirculation in subjects with poor peripheral vascular supply of the lower limb. $B r J$ Podiatr $2003 ; 6: 80-4$. 
14. Barker AT, Cain MW. The claimed vasodilatory effect of a commercial permanent magnet foil: results of a double-blind trial. Clin Phys Physiol Meas 1985;6:261-3.

15. Bergman J, Robertson JR, Elia G. Effects of a magnetic field on pelvic floor muscle function in women with stress urinary incontinence. Alternat Ther Health Med 2004;10:70-2.

16. Bondemark L, Kurol J, Larsson A. Long-term effects of orthodontic magnets on human buccal mucosa-a clinical, histological and immunohistochemical study. Eur $J$ Orthod 1998;20-:211-8.

17. Borsa PA, Ligget CL. Flexible magnets are not effective in decreasing pain perception and recovery time after muscle microinjury. J Athl Train 1998:150-5.

18. Brown CS, Ling FW, Wan J, Pilla A. Efficacy of static magnetic field therapy in chronic pelvic pain: a double-blind pilot study. Am J Obstet Gynecol 2002;187:1581-7.

19. Carter R, Aspy CB, Mold J. The effectiveness of magnet therapy for treatment of wrist pain attributed to carpal tunnel syndrome. J Fam Pract 2002;51:38-40.

20. Caselli MA, Clark N, Lazarus S, Velez Z, Venegas L. Evaluation of magnetic foil and PPT insoles in the treatment of heel pain. J Am Podiatr Med Assoc 1997;87:11-6.

21. Chaloupka EC, Kang J, Mastrangelo MA. The effect of flexible magnets on hand muscle strength: a randomized, double-blind study. J Strength Cond Res 2002;16:33-7.

22. Cody DK, Moran JD. Use of biomagnetic therapy to encourage growth in preterm neonates. Neonatal Netw 1999;18:63-4.

23. Colbert AP, Markov MS, Banerji M, Pilla AA. Magnetic mattress pad use in patients with fibromyalgia: a randomized double-blind pilot study. J Back Musculoskeletal Rehabil 1999;13:19-31.

24. Coles R, Bradley P, Donaldson I, Dingle A. A trial of tinnitus therapy with ear-canal magnets. Clin Otolaryngol Allied $\mathrm{Sci}$ 1991;16:371-2.

25. Collacott EA, Zimmerman JT, White DW, Rindone JP. Bipolar permanent magnets for the treatment of chronic low back pain: a pilot study. JAMA 2000;283:1322-5.

26. Dagan Y, Borodkin K. The ineffectiveness of magnotherapy in a patient with obstructive sleep apnea syndrome and cardiovascular comorbidity. Sleep Breath 2004;8:209-12.

27. Dexter D, Jr. Magnetic therapy is ineffective for the treatment of snoring and obstructive sleep apnea syndrome. Wis Med $\mathrm{J}$ 1997;96:35-7.

28. Eccles N. Static magnets prevent leg ulcer recurrence: savings for the NHS? Br J Community Nurs 2006;11:S26,S28-30.

29. Eccles NK. A randomized, double-blinded, placebo-controlled pilot study to investigate the effectiveness of a static magnet to relieve dysmenorrhea. J Alternat Complement Med 2005;11:681-7.

30. Eccles NK, Hollinworth H. A. pilot study to determine whether a static magnetic device can promote chronic leg ulcer healing. $J$ Wound Care 2005;14:64-7.

31. Garrison DW. Effects of natural magnets on the ability to perceive fine touch and two-point discrimination from fingertips. Am J Pain Manage 2004;14:107-16.

32. Harlow T, Greaves C, White A, Brown L, Hart A, Ernst E. Randomised controlled trial of magnetic bracelets for relieving pain in osteoarthritis of the hip and knee. $\mathrm{Br}$ Med J 2004:329:1450-4.

33. Hinman MR. Comparative effect of positive and negative static magnetic fields on heart rate and blood pressure in healthy adults. Clin Rehabil 2002;16:669-74.

34. Hinman MR, Ford J, Heyl H. Effects of static magnets on chronic knee pain and physical function: a double-blind study. Alternat Ther Health Med 2002;8:50-5.

35. Holcomb RR, Parker RA, Harrison MS. Biomagnetics in the treatment of human pain - past, present, future. Environ Med 1991;8:24-60.

36. Holcomb RR, Worthington WB, McCullough BA, McLean MJ Static magnetic field therapy for pain in the abdomen and genitals. Pediatr Neurol 2000;23:261-4.

37. Hong CZ, Lin JC, Bender LF, Schaeffer JN, Meltzer RJ, Causin P. Magnetic necklace: its therapeutic effectiveness on neck and shoulder pain. Arch Phys Med Rehabil 1982;63:462-6.

38. Kanai S, Taniguchi N. Effect of polarity exchangeable permanent magnet on frozen shoulder pain. Pain Clin 2006;18:37-45.
39. Kanai S, Taniguchi N, Kawamoto M, Endo H, Higashino H. Effect of static magnetic field on pain associated with frozen shoulder. Pain Clin 2004;16:173-9.

40. Kim TS. Relation of magnetic field therapy to pain and power over time in persons with chronic primary headache: a pilot study. Visions 2001;9:27-42.

41. Langford J, McCarthy PW. Randomised controlled clinical trial of magnet use in chronic low back pain; a pilot study. Clin Chiroprac 2005;8:13-9.

42. Man D, Man B, Plosker H. The influence of permanent magnetic field therapy on wound healing in suction lipectomy patients: a double-blind study. Plast Reconstr Surg 1999;104:2261-6; discussion $2267-8$.

43. Martel GF, Andrews SC, Roseboom CG. Comparison of static and placebo magnets on resting forearm blood flow in young, healthy men. J Orthop Sports Phys Ther 2002;32:518-24.

44. Mayrovitz HN, Groseclose EE. Effects of a static magnetic field of either polarity on skin microcirculation. Microvasc Res 2005;69: 24-7.

45. Mayrovitz HN, Groseclose EE, Markov M, Pilla AA. Effects of permanent magnets on resting skin blood perfusion in healthy persons assessed by laser Doppler flowmetry and imaging. Bioelectromagnetics 2001;22:494-502.

46. Mikesky AE, Hayden MW. Effect of static magnetic therapy on recovery from delayed onset muscle soreness. Phys Ther Sport 2005;6:188-94.

47. Panagos A, Jensen M, Cardenas DD. Treatment of myofascial shoulder pain in the spinal cord injured population using static magnetic fields: a case series. J Spinal Cord Med 2004;27:138-42.

48. Pope KW, McNally RJ. Nonspecific placebo effects explain the therapeutic benefit of magnets. Sci Rev Alternat Med 2002;6:13-6.

49. Reeser JC, Smith DT, Fischer V, Berg R, Liu K, Untiedt C, et al. Static magnetic fields neither prevent nor diminish symptoms and signs of delayed onset muscle soreness. Arch Phys Med Rehabil 2005;86:565-70.

50. Salvatore JR, Harrington J, Kummet T. Phase I clinical study of a static magnetic field combined with anti-neoplastic chemotherapy in the treatment of human malignancy: initial safety and toxicity data. Bioelectromagnetics 2003;24:524-7.

51. Schall DM, Ishee JH, Titlow LW. Effect of magnetic therapy on selected physical performances. J Strength Cond Res 2003;17: 299-302.

52. Segal N, Huston J, Fuchs H, Holcomb RR, McLean MJ. Efficacy of a static magnetic device against knee pain associated with inflammatory arthritis. J Clin Rheumatol 1999;5:302-5.

53. Segal NA, Toda Y, Huston J, Saeki Y, Shimizu M, Fuchs H, et al. Two configurations of static magnetic fields for treating rheumatoid arthritis of the knee: a double-blind clinical trial. Arch Phys Med Rehabil 2001;82:1453-60.

54. Simoncini L, Giuriati L, Giannini S. Clinical evaluation of the effective use of magnetic fields in podology. Chir Organi Mov 2001:86:243-7.

55. Suomi R, Koceja DM. Effect of magnetic insoles on postural sway measures in men and women during a static balance test. Percept Mot Skills 2001;92:469-76.

56. Sweeney KB, Merrick MA, Ingersoll CD, Swez JA. Therapeutic magnets do not affect tissue temperatures. J Athl Train 2001;36: $27-31$.

57. Szor JK, Holewinski P. Lessons learned in research: an attempt to study the effects of magnetic therapy. Ostomy Wound Manage 2002;48:24-9.

58. Tis LL, Trinkaus MD, Higbie EJ, Johnson BF, McCarty FA. Effects of magnets on concentric and eccentric isokinetic force production of the quadriceps group. Isokinet Exerc Sci 2000;8: $217-21$.

59. Vallbona C, Hazlewood CF, Jurida G. Response of pain to static magnetic fields in postpolio patients: a double-blind pilot study. Arch Phys Med Rehabil 1997:78:1200-3.

60. Weintraub MI. Magnetic bio-stimulation in painful diabetic peripheral neuropathy: a novel intervention-a randomized, doubleplacebo crossover study. Am J Pain Manage 1999;9:8-17.

61. Weintraub MI. Chronic submaximal magnetic stimulation in peripheral neuropathy: is there a beneficial therapeutic relationship? Am J Pain Manage 1998;8:12-8. 
62. Weintraub MI, Cole SP. Neuromagnetic treatment of pain in refractory carpal tunnel syndrome: an electrophysiological and placebo analysis. J Back Musculoskel Rehabil 2000;15:77-81.

63. Weintraub MI, Steinberg RB, Cole SP. The role of cutaneous magnetic stimulation in Failed Back Syndrome. Sem Integrat Med 2005;3:101-3

64. Weintraub MI, Wolfe GI, Barohn RA, Cole SP, Parry GJ, Hayat G, et al. Static magnetic field therapy for symptomatic diabetic neuropathy: a randomized, double-blind, placebocontrolled trial. Arch Phys Med Rehabil 2003;84:736-46.

65. Winemiller MH, Billow RG, Laskowski ER, Harmsen WS. Effect of magnetic vs sham-magnetic insoles on plantar heel pain: a randomized controlled trial. JAMA 2003;290:1474-8.
66. Winemiller MH, Billow RG, Laskowski ER, Harmsen WS. Effect of magnetic vs sham-magnetic insoles on nonspecific foot pain in the workplace: a randomized, double-blind, placebo-controlled trial. Mayo Clin Proc 2005;80:1138-45.

67. Wolsko PM, Eisenberg DM, Simon LS, Davis RB, Walleczek J, Mayo-Smith M, et al. Double-blind placebo-controlled trial of static magnets for the treatment of osteoarthritis of the knee: results of a pilot study. Alternat Ther Health Med 2004;10:36-43.

68. Brown CS, Ling FW, Wan JY, Pilla AA. Efficacy of static magnetic field therapy in chronic pelvic pain: a double-blind pilot study. Am J Obstet Gynecol 2002;187:1581-7.

Received April 23, 2007; accepted August 09, 2007 


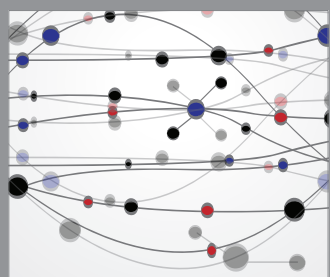

The Scientific World Journal
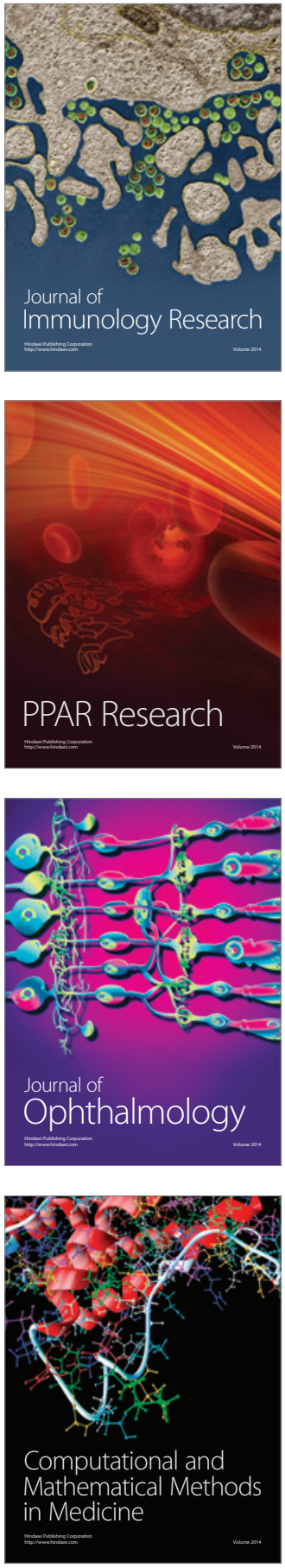

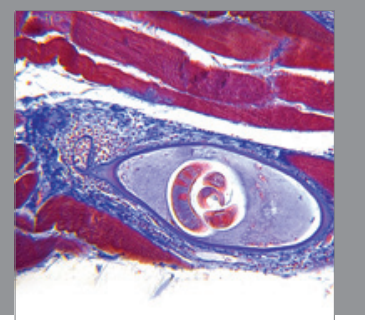

Gastroenterology

Research and Practice
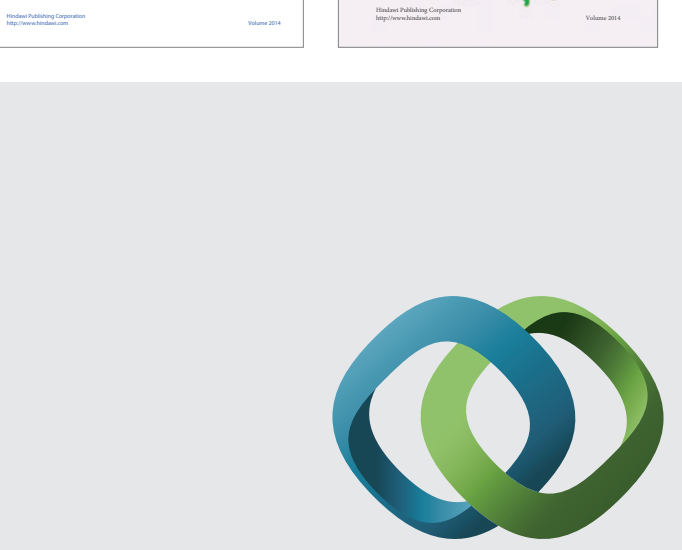

\section{Hindawi}

Submit your manuscripts at

http://www.hindawi.com
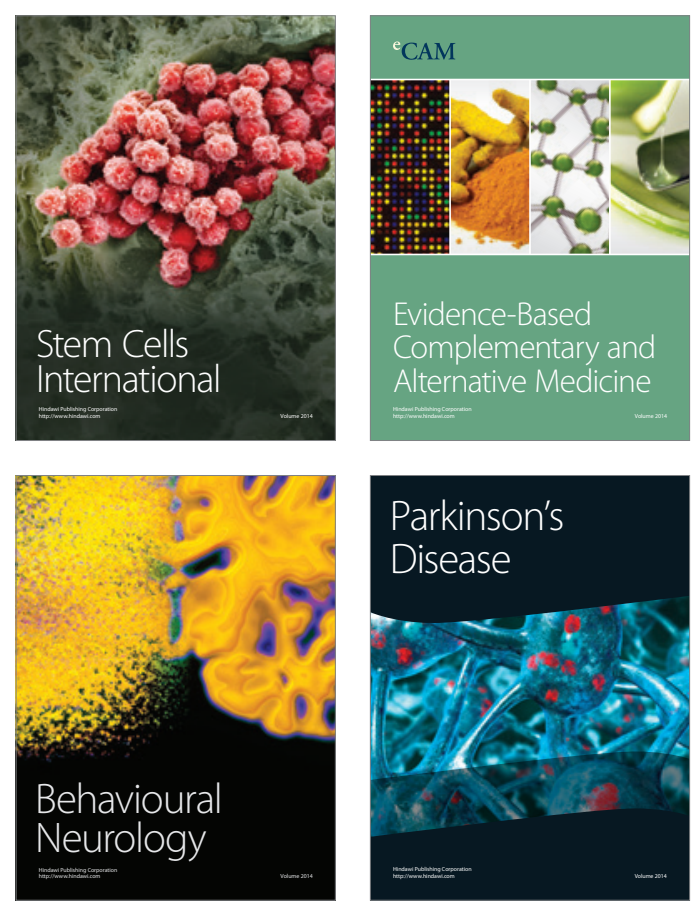

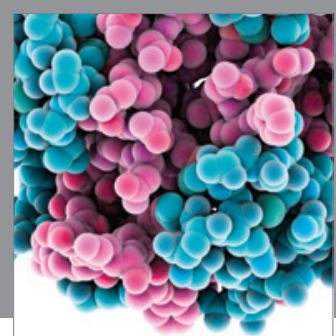

Journal of
Diabetes Research

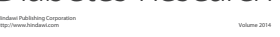

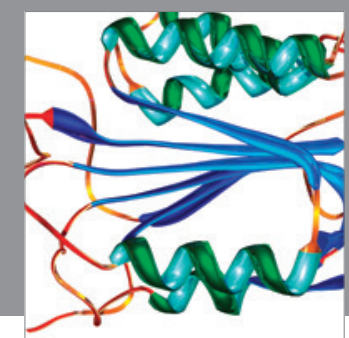

Disease Markers
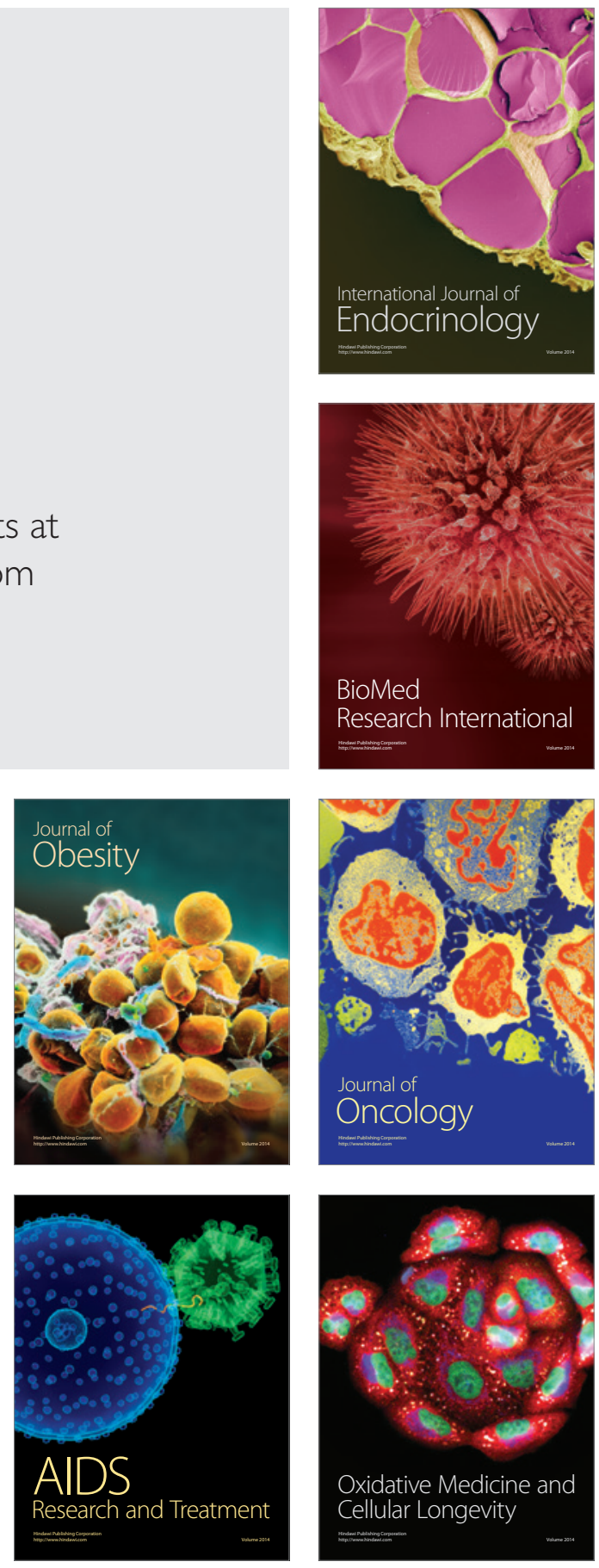